\title{
Recovery and germination of seeds after passage through the gut of Kazakh sheep on the north slope of the Tianshan Mountains
}

\author{
Shulin Wang ${ }^{1}$, Weihua Lu ${ }^{1 *}$, Narkes Waly ${ }^{1}$, Chunhui Ma ${ }^{1}$, Qianbing Zhang ${ }^{1}$ and Chuanjian Wang ${ }^{2}$ \\ ${ }^{1}$ College of Animal Science and Technology; ${ }^{2}$ College of Information Science and Technology, Shihezi University, \\ Shihezi, Xinjiang 832000, China
}

(Received 9 July 2016; accepted after revision 12 January 2017)

\begin{abstract}
Endozoochorous dispersal of seeds by livestock has long attracted the attention of grassland scientists. However, little is known about seed dispersal after ingestion by Kazakh sheep on dry grasslands in the Tianshan Mountains. The objective of this experiment was to learn more about the recovery and germinability of seeds from 17 plant species after either actual or simulated ingestion (i.e. insertion through a rumen fistula) by Kazakh sheep. The passage time of seeds through the sheep gut ranged from 12 to $96 \mathrm{~h}$. More than $80 \%$ of all recovered seeds were defecated 24 $48 \mathrm{~h}$ after ingestion. The mean retention time of seeds in the gut ranged from 27.3 to $42.2 \mathrm{~h}$. Seed recovery percentage ranged between 12.6 and $17.6 \%$ for leguminous species and between 0.8 and $3.2 \%$ for gramineous species. Seed recovery percentage was positively correlated with seed mass, but negatively correlated with seed shape. The germination percentages of the gramineous species were greater in the non-ingested treatment (66-98\%) than in the simulated ingestion treatment (3-10\%). In contrast, for leguminous species, seed germination percentages were greater in the simulated ingestion treatment (23-70\%) than in the non-ingested one (5-12\%). Seed germination percentage after simulated ingestion was positively correlated with seed mass, but negatively correlated with seed shape. In conclusion, leguminous seeds were more likely than gramineous ones to pass through the gut of Kazakh sheep and then germinate. Free-ranging Kazakh sheep can contribute to the spread of plant species, especially leguminous species, in the Tianshan Mountains.
\end{abstract}

Keywords: dry grassland, gut retention time, seed recovery, seed germination, seed dispersal

\footnotetext{
* Correspondence

E-mail: 1051337@qq.com
}

\section{Introduction}

Grazing livestock are one of the most important endozoochorous seed dispersal vectors in grasslands (Archer and Pyke, 1991; Gökbulak and Call, 2009). Seeds can be retained for long periods in the gut of livestock, thus allowing rapid seed dispersal as the animals travel (Pakeman, 2001; Mouissie et al., 2005b; Cosyns and Hoffmann, 2005). Several reports indicate that seedling emergence and growth are promoted by organic matter and nutrients in livestock dung (Woldu and Saleem, 2000; Traveset et al., 2001; Nchanji and Plumptre, 2003). However, other studies indicate that dung can suppress seedling development, especially during early growth stages (Uytvanck et al., 2010; Milotić and Hoffman, 2016). Overall, seed ingestion by livestock can increase species richness and affect large-scale spatial community composition in grazed systems by intensifying intercommunity seed flow (Malo et al., 2000; Cosyns et al., 2005a).

Significant attention has been paid to the role of grazing mammals as endozoochorous dispersers of dry-fruited seeds after Janzen (1984) proposed the 'foliage is the fruit' hypothesis. Researchers have investigated the role of many ruminants in seed dispersal, including cattle (Doucette and Mccaughey, 2001; Gökbulak and Call, 2009), goat (Baraza and Valiente-Banuet, 2008; Mancilla-Leytón et al., 2011), sheep (Manzano et al., 2005), sika deer (Ishikawa, 2010), yak (Yu et al., 2012), and Tibetan sheep (Yu et al., 2012). However, little is known about the dispersal of seeds after ingestion by Kazakh sheep grazing on dry grasslands. Compared with other breeds, Kazakh sheep have evolved special adaptations to the harsh environments in which they live (Adeli and Chen, 2008). Kazakh sheep traditionally graze on dry grasslands on the north slope of the Tianshan Mountains in autumn and winter when plant seeds are mature. There are currently 5 million Kazakh sheep on the north slope of the Tianshan Mountains (Jia and Wang, 2013). 
The retention time of seeds in the digestive tract varies, depending on seed traits as well as on the type of animal (Gökbulak, 2003). Blackshaw and Rode (1991) reported that small seeds passed through the digestive tract of cattle faster than large seeds; however, this relationship was not observed by either Simao and Jones (1987) or Gökbulak and Call (2009). Digestion can enhance or reduce germination depending on seed traits (Simao and Jones, 1987). Passage through the gut of domestic goats greatly increased the germination of leguminous seeds but reduced the germination of gramineous seeds (Baraza and Valiente-Banuet, 2008).

Kazakh sheep preferentially consume gramineous and leguminous plants in the dry grasslands of the Tianshan Mountains. However, there is no information about the endozoochorous dispersal of ingested seeds in the natural grasslands of Xinjiang Province. The objectives of this study were (i) to measure the dimensions (i.e. mass, length, width, thickness and shape) of seeds of 17 wild plant species (13 gramineous and 4 leguminous species) that are common on the north slope of the Tianshan Mountains, (ii) to determine temporal patterns in the defecation of seeds after ingestion by Kazakh sheep, and (iii) to determine the germinability of seeds after simulated ingestion. The latter objective was accomplished using seeds that had been placed in the rumen of fistulated sheep for $22-46 \mathrm{~h}$.

\section{Materials and methods}

\section{Study site}

Seed samples were collected in the dry grassland of the Ziniquan sheep breeding farm, which is located on the north slope of the Tianshan Mountains (435' $44^{\circ} 03^{\prime} \mathrm{N}, 85^{\circ} 40^{\prime}-85^{\circ} 59^{\prime} \mathrm{E}$ ) in Xinjiang Province. The region has a temperate continental climate. The mean annual temperature is $7.2^{\circ} \mathrm{C}$. The maximum average monthly temperature is $26.6^{\circ} \mathrm{C}$ in July. The minimum average monthly temperature is $-18.5^{\circ} \mathrm{C}$ in January. The mean annual precipitation is $231 \mathrm{~mm}$, with most precipitation falling between June and August. This area is important as autumn and winter pasture under the region's traditional grazing system. The vegetation consists predominantly of gramineous and leguminous plants. The soil types are typical grassland chernozem, chestnut soil and calcic brown soil. The grassland types are temperate desert steppe and temperate steppe.

\section{Seed collection and seed attributes}

Mature seeds were collected from over 100 individual plants of 17 species between August and October in 2013 (Table 1). The plant species are all perennials. Most of the species are common in temperate grasslands and were previously observed germinating in herbivore dung. The seeds were taken to the laboratory, air dried, and then stored in brown paper envelopes at $-4^{\circ} \mathrm{C}$ to maintain vigor. The seed mass of each species was determined by weighing three subsamples of air-dried seeds (100 seeds per subsample; $0.01 \mathrm{mg}$ precision). The dimensions (length, width and height) of 10 random seeds were measured using a stereoscopic microscope ( $25 \mu \mathrm{m}$ precision). Seed length was defined as the longest of the three dimensions. Seed shape (i.e. divergence from sphericity) was expressed as the variance in seed dimension after dividing each dimension by the seed length (Thompson et al., 1993) (Table 1).

Table 1. Selected characteristics (mass, length, width, thickness, shape) of the seeds of the perennial plant species used

\begin{tabular}{|c|c|c|c|c|c|c|}
\hline Family & Species name & Seed mass (g/100 seeds) & Length (mm) & Width (mm) & Thickness (mm) & Shape \\
\hline \multirow{12}{*}{ Gramineae } & Achnatherum inebrians & 0.30 & 6.92 & 0.89 & 0.88 & 0.17 \\
\hline & Bromus inermis & 0.25 & 9.14 & 1.72 & 0.33 & 0.18 \\
\hline & Melica transsilvanica & 0.07 & 1.91 & 0.55 & 0.80 & 0.10 \\
\hline & Agropyron desertorum & 0.25 & 6.89 & 0.82 & 1.26 & 0.16 \\
\hline & Agropyron cristatum & 0.24 & 9.33 & 0.68 & 1.04 & 0.18 \\
\hline & Elytrigia repens & 0.79 & 12.56 & 1.67 & 0.87 & 0.18 \\
\hline & Roegneria mutabilis & 0.34 & 8.06 & 1.23 & 0.70 & 0.17 \\
\hline & Roegneria sinkiangensis & 0.33 & 8.24 & 1.20 & 0.89 & 0.17 \\
\hline & Dactylis glomerata & 0.07 & 5.35 & 0.78 & 0.52 & 0.17 \\
\hline & Hordeum bogdanii & 0.16 & 13.96 & 0.64 & 1.07 & 0.20 \\
\hline & Leymus tianschanicus & 0.54 & 14.03 & 0.94 & 1.54 & 0.19 \\
\hline & Agrostis turkestanica & 0.01 & 1.04 & 0.32 & 0.42 & 0.09 \\
\hline \multirow{5}{*}{ Leguminosae } & Puccinellia tenuiflora & 0.01 & 2.02 & 0.36 & 0.53 & 0.14 \\
\hline & Sophora alopecuroides & 2.56 & 4.22 & 3.16 & 2.39 & 0.03 \\
\hline & Vicia tenuifolia & 1.19 & 2.56 & 2.31 & 1.74 & 0.02 \\
\hline & Lathyrus pratensis & 1.02 & 3.05 & 2.33 & 1.55 & 0.04 \\
\hline & Glycyrrhiza glabrae & 0.57 & 2.31 & 1.99 & 2.03 & 0.004 \\
\hline
\end{tabular}




\section{Test animals and treatments}

The six male Kazakh sheep in the study were similar in weight (weight $42 \pm 1.25 \mathrm{~kg}$ ) and in age ( 2 years old). The sheep were kept in individual metabolic crates $(1.4 \mathrm{~m} \times$ $0.6 \mathrm{~m}$ ) with a faeces collection system (Fig. 1). The sheep were fed a seed-free diet for 7 days. On day 8, three sheep were fed 3000 seeds of each plant species in a single meal. The seeds were mixed with $300 \mathrm{~g}$ of feed concentrate to facilitate intake. The dung pellets of these sheep were collected $6,12,24,36,48,72$ and $96 \mathrm{~h}$ after ingestion. The pellets were dried at room temperature and then stored in the laboratory. The seeds from the feeding experiment were used to determine seed recovery percentage and mean retention time (MRT).

The seed recovery percentages were low in the feeding experiment. Therefore, a simulated ingestion experiment was conducted so that there were enough seeds to accurately determine seed germination percentage (Peco et al., 2006). A permanent rumen fistula was made in the three sheep that were not used in the feeding experiment. Heat-sealed nylon bags $(11 \mathrm{~cm} \times 7 \mathrm{~cm}$, $40 \mu \mathrm{m}$ pore size) containing 100 seeds of each plant species were introduced through the fistula. Most seeds are retained in the rumen for $22-46 \mathrm{~h}$ and in a heavily acid part of the gut (abomasum and duodenum) for $2-4 \mathrm{~h}$ (Warner, 1981). To simulate these conditions, the bags were incubated for 22,34 or $46 \mathrm{~h}$ inside the sheep rumen. After removal from the rumen, each bag and its contents were rinsed with tap water and placed in a $0.1 \mathrm{~N}$ pepsin-hydrochloric acid solution for $2 \mathrm{~h}$ in an oven at $40^{\circ} \mathrm{C}$. The solution was produced by dissolving $2 \mathrm{~g}$ of pepsin (Merck reference 1.07190.1000 with activity 2000FIP-U/g) in 1 litre of $0.1 \mathrm{~N} \mathrm{HCl}$. The seeds from the simulated ingestion experiment were used to determine germination percentage.

\section{Recovery, mean retention time and germination}

The total mass of dung pellets was weighed for each sheep at each time interval. A $100 \mathrm{~g}$ subsample of the pellets was manually crushed and then the number of seeds of each plant species was determined. The recovery percentage of the seeds (RPS) was estimated for each plant species using the following equation:

$$
R P S=m_{f} s_{r} / 100 s
$$

where $m_{f}$ is the total mass of dung defecated within each time interval, $s_{r}$ is the average number of seeds found in $100 \mathrm{~g}$ of pellet, and $s$ is the number of seeds ingested by the sheep. The MRT of seeds in the digestive tract was calculated using the following equation:

$$
M R T=\sum_{i=1}^{n} m_{i} t_{i} / \sum_{i=1}^{n} m_{i}
$$

where $m_{i}$ is the number of seeds defecated at time $t_{i}$ after ingestion by the sheep.

The germination percentage of seeds from the simulated ingestion study was compared with that of non-ingested seeds. All seeds were disinfected by immersion in a $1 \%$ sodium hypochlorite solution for $2 \mathrm{~min}$ and then rinsed with sterile distilled water for $10 \mathrm{~min}$. The seeds were placed on moist filter paper in 5-cm Petri dishes. Each Petri dish contained 25 seeds. There were four replicates per treatment. The incubations were conducted in controlled environment chambers with $16 \mathrm{~h}$ light at $25^{\circ} \mathrm{C}$ and $8 \mathrm{~h}$ of darkness at $15^{\circ} \mathrm{C}$. The filter paper was remoistened with distilled water as necessary. The incubation conditions allow for the germination of a large range of plant species (Picard et al., 2015). The dishes were examined daily. Seeds were considered to have germinated when the root was 1-2 mm long. Seeds that had germinated were counted and then removed from the dishes. The germination percentages in this paper are the average of the three incubation times (i.e. 22, 34 and $46 \mathrm{~h})$.
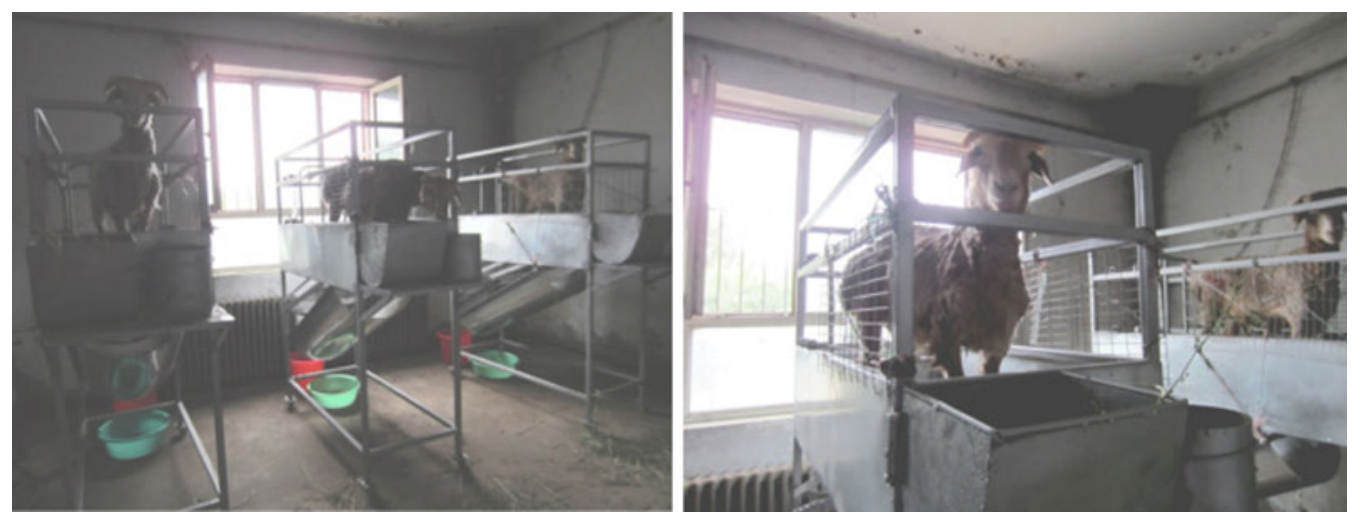

Figure 1. The individual metabolic crates with a faeces collection system. 


\section{Data analysis}

Analysis of variance was conducted to evaluate differences among the plant species in seed recovery percentage and MRT. The data were tested for normality with the Kolmogorov-Smirnov test. The Tukey test was used to verify significant differences among species. Pearson's correlation was used to test how seed recovery and seed germination percentage after ingestion were related to seed mass and seed shape. The statistical analyses were conducted using SPSS 17.0 for Windows (SPSS Inc., Chicago, IL, USA). A phylogenetic tree of the plant species was drawn with Phylomatic software version 3.0.

\section{Results}

The mass and dimensions of the rather elongated gramineous seeds were as follows (means of 13 species with ranges in parentheses): 100 -seed mass, $0.26 \mathrm{~g}$ (0.01-0.79 g); length, $7.65 \mathrm{~mm}$ (1.04-14.03 mm); width, $0.91 \mathrm{~mm} \quad(0.32-1.72 \mathrm{~mm})$; thickness, $0.83 \mathrm{~mm} \quad(0.33-$ $1.54 \mathrm{~mm})$; divergence from sphericity, $0.16(0.09-0.19)$ (Table 1). In comparison, the rather rounded leguminous seeds had the following characteristics (means of four species with ranges in parentheses): 100-seed mass, $1.34 \mathrm{~g}$ (0.57-2.56 g); length, $3.04 \mathrm{~mm}$ (2.31-4.22 $\mathrm{mm})$; width, $2.45 \mathrm{~mm}(1.99-3.16 \mathrm{~mm})$; thickness, 1.93 $\mathrm{mm}(1.55-2.39 \mathrm{~mm})$; divergence from sphericity, 0.02 (0.004-0.03) (Table 1).

There was a clear peak in the recovery of seeds of all plant species between 24 and $48 \mathrm{~h}$ after ingestion (Fig. 2). More than $80 \%$ of all recovered seeds were defecated during this period. No seeds were recovered

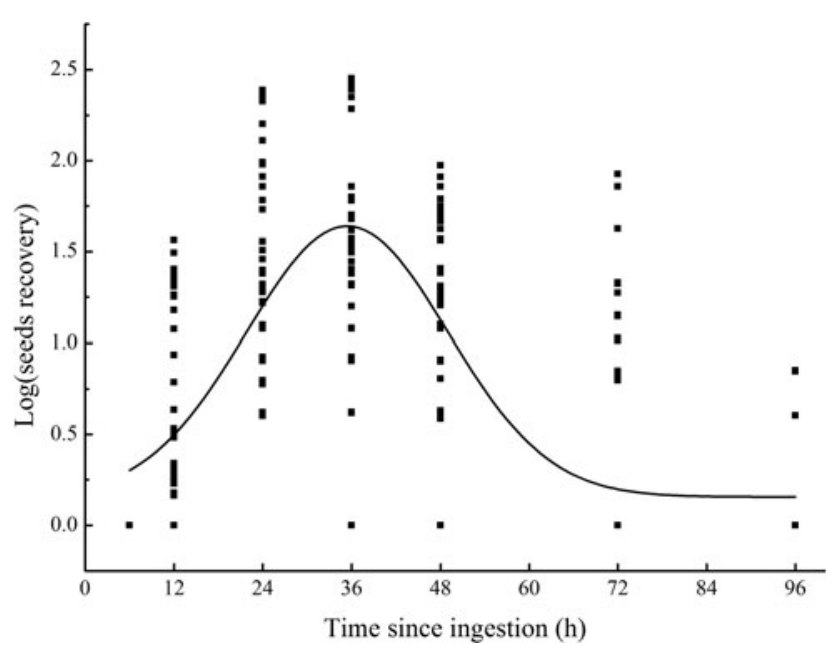

Figure 2. Temporal changes in seed recovery after ingestion by Kazakh sheep. The data were fitted to a Gaussian model: $y=0.16+1.48 \mathrm{e}^{-2((x-35.42) / 27.27) 2}, r^{2}=0.55, F\left(d f_{1}=16, d f_{2}=34\right)=$ 311.16, $P<0.0$. from dung during the first $6 \mathrm{~h}$ after feeding. Seeds from three plant species (i.e. Dactylis glomerata, Agrostisis turkestanica and Melica transsilvanica) were still being recovered in dung $96 \mathrm{~h}$ after feeding.

There were significant differences among plant species in the number of seeds recovered from sheep dung $\left[F\left(d f_{1}=16, d f_{2}=34\right)=1924.07, P<0.01\right]$. The recovery percentages of the four leguminous species (12.7$17.5 \%)$ were significantly greater than those of the 13 gramineous species (0.8-3.2\%) (Table 2).

The MRT of most species was between 30 and $39 \mathrm{~h}$. There were significant differences in MRT among species $\left[F\left(d f_{1}=16, d f_{2}=34\right)=7.511, P<0.05\right]$. Achnatherum inebrians had the longest MRT $(42.2 \mathrm{~h})$, followed by D. glomerata $(41.9 \mathrm{~h})$ and B. inermis $(40.7 \mathrm{~h})$. Agropyron cristatum had the lowest MRT (27.3 h) (Table 2).

Simulated ingestion significantly affected seed germination percentage [Fig. $3 ; \quad F\left(d f_{1}=16, d f_{2}=34\right)=$ $60403.38, P<0.01]$. The germination percentage of all 13 gramineous species was significantly less in the simulated ingestion treatment $(3.18-10.12 \%)$ than in the non-ingested treatment $(66.67-97.67 \%)\left[F\left(d f_{1}=16\right.\right.$, $\left.\left.d f_{2}=34\right)=1052.1, P<0.01\right]$. Among the gramineous species, $P$. tenuiflora and $H$. bogdanii had the highest germination percentage after simulated ingestion, whereas $A$. cristatum had the lowest germination percentage. The germination percentage of all four leguminous species was significantly greater in the simulated ingestion treatment $(22.55-70.22 \%)$ than in the non-ingested treatment $(5.33-12.33 \%)\left[F\left(d f_{1}=\right.\right.$ $\left.\left.16, d f_{2}=34\right)=1595.16, P<0.01\right]$. The germination percentage of the leguminous species after simulated

Table 2. Total recovery percentages and mean retention times of ingested seeds

\begin{tabular}{lll}
\hline Species & $\begin{array}{l}\text { Total recovery } \\
\text { percentages }(\%)\end{array}$ & $\begin{array}{l}\text { Mean retention } \\
\text { time }(\mathrm{h})\end{array}$ \\
\hline Achnatherum inebrians & $2.64 \pm 0.51^{\mathrm{cde}}$ & $42.20 \pm 1.57^{\mathrm{a}}$ \\
Bromus inermis & $3.02 \pm 0.12^{\mathrm{cd}}$ & $41.89 \pm 3.92^{\mathrm{ab}}$ \\
Melica transsilvanica & $0.78 \pm 0.09^{\mathrm{e}}$ & $40.74 \pm 4.17^{\mathrm{abc}}$ \\
Agropyron desertorum & $1.09 \pm 0.48^{\mathrm{e}}$ & $37.50 \pm 2.35^{\mathrm{abcd}}$ \\
Agropyron cristatum & $2.38 \pm 0.32^{\mathrm{cde}}$ & $37.50 \pm 4.46^{\mathrm{abcd}}$ \\
Elytrigia repens & $1.27 \pm 0.16^{\mathrm{de}}$ & $37.17 \pm 1.11^{\mathrm{abcde}}$ \\
Roegneria mutabilis & $1.29 \pm 0.11^{\mathrm{de}}$ & $27.30 \pm 2.34^{\mathrm{f}}$ \\
Roegneria sinkiangensis & $2.11 \pm 0.31^{\mathrm{cde}}$ & $34.45 \pm 1.29^{\mathrm{abcdef}}$ \\
Dactylis glomerata & $2.00 \pm 0.43^{\mathrm{cde}}$ & $32.83 \pm 2.98^{\mathrm{cdef}}$ \\
Hordeum bogdanii & $1.61 \pm 0.38^{\mathrm{cde}}$ & $34.00 \pm 3.00^{\mathrm{bcdef}}$ \\
Leymus tianschanicus & $3.40 \pm 0.61^{\mathrm{c}}$ & $38.04 \pm 2.14^{\mathrm{abcd}}$ \\
Agrostis turkestanica & $3.22 \pm 0.35^{\mathrm{c}}$ & $39.41 \pm 2.90^{\mathrm{abcd}}$ \\
Puccinellia tenuiflora & $1.90 \pm 0.19^{\mathrm{cde}}$ & $35.93 \pm 2.86^{\mathrm{abcde}}$ \\
Sophora alopecuroides & $17.46 \pm 1.64^{\mathrm{a}}$ & $32.51 \pm 0.87^{\mathrm{def}}$ \\
Vicia tenuifolia & $13.33 \pm 0.86^{\mathrm{b}}$ & $35.67 \pm 1.17^{\mathrm{abcde}}$ \\
Lathyrus pratensis & $12.64 \pm 0.48^{\mathrm{b}}$ & $29.38 \pm 1.22^{\mathrm{ef}}$ \\
Glycyrrhiza glabrae & $15.98 \pm 1.07^{\mathrm{a}}$ & $39.49 \pm 2.38^{\mathrm{abcd}}$ \\
\hline
\end{tabular}

Values are presented as means \pm standard error $(n=3)$. Values within a column followed by a different letter are significantly different at $P<0.05$. 

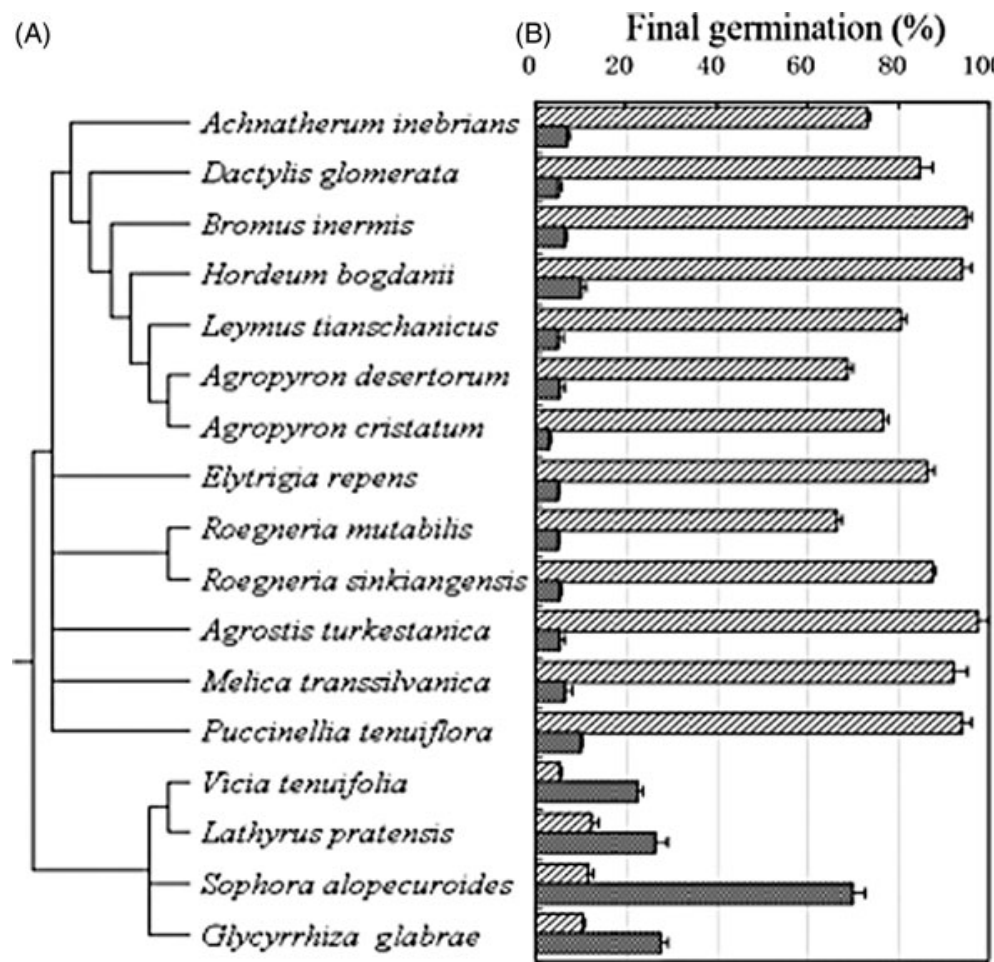

Tumb
Non-ingested
Simulated ingestion

Figure 3. A: working phylogeny of the 17 plant species in this experiment. B: final seed germination percentage in the non-ingested and simulated ingestion treatments. Values are means \pm SD.

ingestion decreased in the order $S$. alopecuroides $>$ L. pratensis $>$ G. glabrae $>V$. tenuifolia (Fig. 3).

Seed recovery percentage was positively and most significantly correlated with seed mass $(r=0.91, P<$ 0.01 ). Seed recovery percentage was significantly negatively correlated with seed shape $(r=-0.71, P<0.05)$. The germination percentages were negatively correlated with seed shape $(r=-0.93, P<0.01)$. Mean retention time was not significantly correlated with either seed mass $(r=0.18, P>0.05)$ or seed shape $(r=-0.44$, $P>0.05)$.

\section{Discussion}

The distance and effectiveness of seed dispersal is determined by the combined effects of (i) seed retention time in the vector's digestive system, (ii) the spatial extent of its movements, and (iii) the ability of the seeds to germinate once released (Picard et al., 2015). The present study indicated a clear peak in seed defecation between 24 and $48 \mathrm{~h}$ after ingestion. Previous studies have shown a similar time span with sheep (Manzano et al., 2005). Seed recovery percentages after ingestion ranged from 0.8 to $17.5 \%$. Those percentages agreed with other studies involving small ruminants. For example, seed recovery percentages after ingestion were $0-28 \%$ (Yu et al., 2012) and 10.4-23.0\% (Manzano et al., 2005) in sheep, $7.4-17.4 \%$ in goat (Robles et al., 2005) and $0.5-42.0 \%$ in fallow deer
(Mouissie et al., 2005a). A likely reason for the relatively low recovery percentage in these studies is that small digestive tracts increase the likelihood of seeds contacting the gut wall which damages the seed by abrasion (Razanamandranto et al., 2004).

The MRT of seeds in the digestive tract of Kazakh sheep ranged between 27 and $42 \mathrm{~h}$. In comparison, other researchers have reported MRT values of 41 to $66 \mathrm{~h}$ in sheep (Illius and Gordon, 1992; Cosyns et al., $2005 \mathrm{~b})$. These values are greater than those of rabbit and equid species $(30-31 \mathrm{~h})$, roe deer $(18-36 \mathrm{~h})$, and red deer (3-36 h) (Picard et al., 2015). The MRT of ingested seeds in this study varied depending on plant species; however, the results indicate that the time span was long enough to result in seed dispersal in the grassland. Under the traditional grazing system in the Tianshan Mountains, Kazakh sheep move freely in the grassland. A previous report indicated that freegrazing Kazakh sheep move about $7-10 \mathrm{~km}$ per day (Wang et al., 2016). This distance is far less than the distance of $25-30 \mathrm{~km}$ per day that other authors have reported (Klein, 1981; Manzano et al., 2005). Obviously, these distances are affected by grazing management.

Many studies have indicated that ingestion reduces hard-seededness, with a greater proportion of seeds capable of germinating after ingestion (Russi and Roberts, 1992; Malo and Suárez, 1996; Milotić and Hoffmann, 2016). However, other researchers have reported that germination declined when soft-coated 
or non-dormant seeds were soaked in rumen fluid ( $\mathrm{Yu}$ et al., 2012). Hard-seededness is a common feature and the main mechanism of seed dormancy in legumes. In our study, simulated ingestion increased the germinability of S. alopecuroides, $V$. tenuifolia, $L$. pratensis and G. glabrae. This indicated that digestion can break dormancy and promote germination of leguminous seed. In contrast, simulated ingestion reduced the germination percentage of seeds from all 13 gramineous species. One possibility is that these seeds were either soft-coated or non-dormant. It should be noted that the conditions in this experiment simulated the environment of one specific part of the digestive system (i. e. rumen). In fact, the chemical composition varies among different parts of the digestive systems, as enzyme activity and $\mathrm{pH}$ differ between the mouth, rumen, stomach and intestines. These factors could have significant effect on seed germinability.

The seed recovery percentages were too low to accurately determine the germination percentage of the ingested seeds in this study. Therefore, we had to simulate the effects of ingestion. The effects of mastication, however, should be overlooked. Some plant species have seeds with hard seed coats that cause physical dormancy. For those plant species (e.g. many species in the Leguminosae and Cistaceae families), physical damage caused by chewing might break the seed coat and enhance germination. In other cases chewing may damage seeds and reduce germinability (Milotić and Hoffmann, 2016). Ruminants generally only chew enough to get the proper mixture of food and saliva to form a bolus and facilitate swallowing (Church, 1976). It is unclear whether seeds are damaged more by mastication or by the harsh environment of the reticulorumen. Seed size is probably also a factor, because small seeds are more likely to escape mastication (Russi and Roberts, 1992; Gökbulak, 2006).

Bruun and Poschlod (2006) and D'Hondt and Hoffmann (2011) observed no relationship between endozoochorous dispersal potential and seed characteristics such as mass, shape (roundness) and thickness. Nevertheless, Janzen (1984) provided a good hypothesis of ecological interaction for seed dispersal through ingestion and defecation by large herbivores. According to Janzen (1984), large and round seeds of Leguminosae are best adapted to endozoochory. Our results also showed that seed recovery percentage and germination percentage were both related to seed mass and seed shape. Large and round seeds (e.g. those of S. alopecuroides, $V$. tenuifolia, L. pratensis and G. glabrae) had high recovery and germination percentages, whereas small and long seeds (e.g. those of B. inermis and H. bogdanii) had low recovery and germination percentages. Conflicting ideas about the relationship between seed characteristics and seed dispersal potential may be due to differences in plant species. The MRT was not significantly correlated with either seed mass or seed shape. Similarly, Cosyns et al. (2005b) reported that MRT was not significantly correlated with seed germination, seed recovery, or seed characteristic. This may be the result of complex interplay between animal and plant species.

The above results imply that the grazing activities of Kazakh sheep may contribute to the gathering of plant seeds under traditional seasonal grazing in Xinjiang Province. This is especially true in autumn and winter, when most plants still retain seeds. These seeds are available for consumption by moving livestock. Although the cost of gut passage for dry-fruited species is undoubtedly high (Traveset et al., 2002), ingestion can be advantageous for plant establishment due to the potential benefits of long distance dispersal. The results presented in Table 2 and Fig. 3 indicate that seed recovery and germination percentages of leguminous species were both relatively high after ingestion by Kazakh sheep. The MRT, recovery percentage and germination percentage indicate potential for long distance seed dispersal. This dispersal capacity could increase the heterogeneity among plant communities under free-range conditions.

\section{Acknowledgements}

This study was funded by the National Natural Science Foundation of China (no. 31360568; no. 31560659) and the Specialized Research Fund for the Doctoral Program of Higher Education of China (no. 20126518120004). The authors would like to thank Dr Hao Li for technical support with the ruminal and small intestinal fistula surgery. We wish to thank Dr William J. Gale for his suggestions and improvements to the language in this manuscript.

\section{References}

Adeli, A. and Chen, W.G. (2008) The suggestions about resources and utilizing of Hazakah sheep. Animal Husbandry in XinJiang 11, 32-33.

Archer, S. and Pyke, D.A. (1991) Plant-animal interactions affecting plant establishment and persistence on revegetated rangeland. Journal of Range Management 44, 558-565.

Baraza, E. and Valiente-Banuet, A. (2008) Seed dispersal by domestic goats in a semiarid thornscrub of Mexico. Journal of Arid Environments 72, 1973-1976.

Blackshaw, R.E. and Rode, L.M. (1991) Effect of ensiling and rumen digestion by cattle on weed seed viability. Weed Science 39, 104-108.

Bruun, H.H. and Poschlod, P. (2006) Why are small seeds dispersed through animal guts: large numbers or seed size per se? Oikos 113, 402-411.

Church, D.C. (1976) Ingestion and mastication of feed. In Church, D. C. (ed), Digestive Physiology and Nutrition of 
Ruminants, vol. 1, Digestive Physiology, 2nd edition, pp. 46-60. Corvallis, OR: O and B Books.

Cosyns, E. and Hoffmann, M. (2005) Horse dung germinable seed content in relation to plant species abundance, diet composition and seed characteristics. Basic and Applied Ecology 6, 11-24.

Cosyns, E., Claerbout, S., Lamoot, I. and Hoffmann, M. (2005a) Endozoochorous seed dispersal by cattle and horse in a spatially heterogeneous landscape. Plant Ecology 178, 149-162.

Cosyns, E., Delporte, A., Lens, L. and Hoffmann, M. (2005b) Germination success of temperate grassland species after passage through ungulate and rabbit guts. Journal of Ecology 93, 353-361.

D'Hondt, B. and Hoffmann, M. (2011) A reassessment of the role of simple seed traits in mortality following herbivore ingestion. Plant Biology 13, 118-124.

Doucette, K.M. and Mccaughey, W.P. (2001) Seed recovery and germination of reseeded species fed to cattle. Journal of Range Management 54, 575-581.

Gökbulak, F. (2003) Effect of American bison (Bison bison L.) on the recovery and germinability of seeds of range forage species. Grass and Forage Science 57, 395-400.

Gökbulak, F. (2006) Recovery and germination of grass seeds ingested by cattle. Journal of Biological Sciences 6, 23-27.

Gökbulak, F. and Call, C.A. (2009) Grass seedling recruitment in cattle dungpats. Rangeland Ecology and Management 57, 649-655.

Illius, A.W. and Gordon, I.J. (1992) Modelling the nutritional ecology of ungulate herbivores: evolution of body size and competitive interactions. Oecologia 89, 428-434.

Ishikawa, H. (2010) Effects of ingestion of seeds by sika deer (Cervus nippon) and dung presence on their germination in a herbaceous community. Ecological Research 25, 591-598.

Janzen, D.H. (1984) Dispersal of small seeds by big herbivores: foliage is the fruit. American Naturalist 123, 338-353.

Jia, X.S. and Wang, A.F. (2013) The discussion on establishment of reproduction and breeding stystem in Kazak sheep. Grass-Feeding Livestock 1, 9-12.

Klein, J. (1981) La Mesta (2nd edition). Madrid, Spain, Alianza Editorial.

Malo, J.E. and Suárez, F. (1996) Cistus ladanifer recruitment not only fire, but also deer. Acta Oecologica 17, 55-60.

Malo, J.E., Jiménez, B. and Suárez, F. (2000) Herbivore dunging and endozoochorous seed deposition in a Mediterranean dehesa. Journal of Range Management 53, 322-328.

Mancilla-Leytón, J.M., Fernández-Alés, R. and Vicente, A. M. (2011) Plant-ungulate interaction: goat gut passage effect on survival and germination of Mediterranean shrub seeds. Journal of Vegetation Science 22, 1031-1037.

Manzano, P., Malo, J.E. and Peco, B. (2005) Sheep gut passage and survival of Mediterranean shrub seeds. Seed Science Research 15, 21-28.

Milotić, T. and Hoffmann, M. (2016) How does gut passage impact endozoochorous seed dispersal success? Evidence from a gut environment simulation experiment. Basic and Applied Ecology 17, 165-176.

Mouissie, A.M., van der Veen, C.E.J., Veen, G.F.C. and Van Diggelen, R. (2005a) Ecological correlates of seed survival after ingestion by fallow deer. Functional Ecology 19, 284-290.

Mouissie, A.M., Vos, P., Verhagen, H.M.C. and Bakker, J.P. (2005b) Endozoochory by free-ranging, large herbivores: ecological correlates and perspectives for restoration. Basic and Applied Ecology 6, 547-558.
Nchanji, A.C. and Plumptre, A.J. (2003) Seed germination and early seedling establishment of some elephantdispersed species, Banyang-Mbo wildlife Sanctuary, Southwest Cameroon. Journal of Tropical Ecology 19, 229-237.

Pakeman, R.J. (2001) Plant migration rates and seed dispersal mechanisms. Journal of Biogeography 28, 795-800.

Peco, B., Lopez-Merino, L. and Alvir, M. (2006) Survival and germination of Mediterranean grassland species after simulated sheep ingestion: ecological correlates with seed traits. Acta Oecologica 30, 269-275.

Picard, M., Papaïx, J., Gosselin, F., Picot, D., Bideau, E. and Baltzinger, C. (2015). Temporal dynamics of seed excretion by wild ungulates: implications for plant dispersal. Ecology and Evolution 5, 2621-2632.

Razanamandranto, S., Tigabu, M., Neya, S. and Odén, P.C. (2004) Effects of gut treatment on recovery and germinability of bovine and ovine ingested seeds of four woody species from the Sudanian savanna in West Africa. Flora-Morphology, Distribution, Functional Ecology of Plants 199, 389-397.

Robles, A.B., Castro, J., González-Miras, E. and Ramos, M. E. (2005) Effects of ruminal incubation and goats' ingestion on seed germination of two legume shrubs: Adenocarpus decorticans Boiss. and Retama sphaerocarpa (L.) Boiss. Options Méditerranéennes Série A Séminaires Méditerranéens 67, 111-115.

Russi, L. and Roberts, E.H. (1992) The fate of legume seeds eaten by sheep from a Mediterranean grassland. Journal of Applied Ecology 29, 772-778.

Simao, N.M. and Jones, R.M. (1987) Recovery of pasture seed ingested by ruminants. 2. Digestion of seed in sacco and in vitro. Animal Production Science 27, 247-251.

Thompson, K., Band, S.R. and Hodgson, J.G. (1993) Seed size and shape predict persistence in soil. Functional Ecology 7, 236-241.

Traveset, A., Bermejo., T. and Willson, M. (2001) Effect of manure composition on seedling emergence and growth of two common shrub species of Southeast Alaska. Plant Ecology 155, 29-34.

Traveset, A., Verdú, M., Levey, D.J., Silva, W.R. and Galetti, M. (2002) A meta-analysis of the effect of gut treatment on seed germination. International Symposium Workshop on Frugivores and Seed Dispersal 91, 334-339.

Uytvanck, J.V., Milotić, T. and Hoffmann, M. (2010) Interaction between large herbivore activities, vegetation structure, and flooding affects tree seedling emergence. Plant Ecology 206, 173-184.

Wang, C.J., Wang, W.Q., Lu, W.H., Wen, C.L., Yin, X.J. and Zhao, Q.Z. (2016) Feed intake distribution model for herd based on grazing spatio-temporal trajectory data. Transactions of the Chinese Society of Agricultural Engineering 32, 125-130.

Warner, A.C.I. (1981) Rate of passage of digesta through the gut of mammals and birds. Nutrition Abstract and Review 51, 789-820.

Woldu, Z. and Saleem, M.A.M. (2000) Grazing induced biodiversity in the highland ecozone of East Africa. Agriculture Ecosystems and Environment 79, 43-52.

Yu, X.J., Xu, C.L., Wang, F., Shang, Z.H. and Long, R.J. (2012) Recovery and germinability of seeds ingested by yaks and Tibetan sheep could have important effects on the population dynamics of alpine meadow plants on the Qinghai-Tibetan Plateau. Rangeland Journal 34, 249-255. 